BOOK REVIEW

\section{Oxford Handbook of Reproductive Medicine and Family Planning (2nd edn)}

Enda McVeigh, John Guillebaud, Roy Homburg. Oxford, UK: Oxford University Press, 2013. ISBN-13: 978-0-199-65068-2. Price: £32.99. Pages: 416 (flexibound)

This is an excellent resource for health professionals. The book comprises two parts. The first part is on reproductive medicine, and covers hormones, polycystic ovary syndrome, hirsutism, amenorrhoea, menopause and infertility. The second part covers contraception and family planning, encompassing hormonal contraception, intrauterine devices, emergency contraception and sterilisation.

This book offers a brief, detailed discussion on each area with suggestions for further reading. It is pocket-sized and very accessible for revising subject areas. Whilst it may not always provide the reader with sufficient depth of coverage, this book is nevertheless really useful, especially for those individuals starting work in sexual health and contraception, who need a reminder or refresher about specific topics.

\section{Reviewed by Su Everett}

Senior Lecturer, Middlesex University, London, and Senior Nurse Practitioner, Kings College NHS Hospital, London, UK; s.everett@mdx.ac.uk

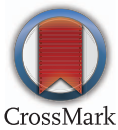

J Fam Plann Reprod Health Care 2015:41:127. doi:10.1136/fprhc-2015-101179 